\title{
Optimization of spillway routes of city aryk networks into open drains in Shymkent
}

Eleu Nauryzbaev ${ }^{1}$, Kanat Baibolov ${ }^{1}$, Ayazgali Medeuov ${ }^{2, *}$, Aidarbek Bolisbek ${ }^{1}$, Kuanish Imanaliev ${ }^{1}$, Zhenisbek Ussenkulov $^{1}$, Zhumadilla Aldiyarov ${ }^{1}$, Bakhytzhan Ismailov ${ }^{1}$

${ }^{1}$ M. Auezov South Kazakhstan State University, Shymkent, Kazakhstan

${ }^{2}$ Department of Oil Production and Construction, Kazakhstan Engineering-Pedagogical University of Friendship between Nations, Shymkent, Kazakhstan

\section{ARTICLE INFO}

\section{Article history:}

Received 31 October 2016

Received in revised form

5 February 2017

Accepted 10 February 2017

\section{Keywords:}

Spillways

Watercourses

Discharge

Outlet

Treatment

Facilities

\begin{abstract}
A B S T R A C T
One of the main problems facing big industrial cities is wastewater with hazardous substances, including petroleum products. A study of methods for optimizing spillways of city flume networks in Shymkent in South Kazakhstan region is presented in this paper. The influxes of flume networks and drainage (ground) water into existing rivers allow determining the aggregate intermediate volume (over a certain period) of surface runoff that enters the watercourses after rains. The estimations were based on data, collected at points of accumulation of surface water and rainwater, discharged into the Badam, Koshkar-Ata, and Karasu Rivers via optimal routes, in accordance with the methods of estimating the discharge of storm runoffs from the territory of settlements and enterprises. The paper characterized water discharges in the city by pollution categories and their nature, presented the main operating parameters of city treatment facilities, provided methods of estimating rainfall floods, a hydrological characteristic of estimated watercourses in the city, and determined the zoning of watercourses for rainwater and meltwater in the city territory.
\end{abstract}

(C) 2017 The Authors. Published by IASE. This is an open access article under the CC BY-NC-ND license (http://creativecommons.org/licenses/by-nc-nd/4.0/).

\section{Introduction}

Nowadays, for purposes of environmental protection, primarily of natural waterbodies, much attention is paid to the treatment of surface rainwater and meltwater (Nekhoroshkov, 2016; Saldaeva et al., 2016). Due to the variety of pollution types, several types of treatment exist. Methods of treating drainage waters can be divided into mechanical, physical and chemical, and biological. In most cases, mechanical treatment facilities are enough to do the job. These are grates, desilting basins, settlers, and filters of various constructions. Mechanical treatment ensures a significant reduction of the content of suspended particles, BOD index (the index that characterizes the pollution level by the biological oxygen demand), and the content of oil. After an hour of desilting, 90\% of suspended matter falls out of rainwater, while the BOD index drops by $50-70 \%$.

\footnotetext{
* Corresponding Author.

Email Address: 150958@mail.ru (A. Medeuov)

https://doi.org/10.21833/ijaas.2017.02.019

2313-626X/C) 2017 The Authors. Published by IASE.

This is an open access article under the CC BY-NC-ND license

(http://creativecommons.org/licenses/by-nc-nd/4.0/)
}

Rainwater treatment for oil is a more complicated task. In general, mechanical treatment does not reduce the content of oil to permissible norms (Everett et al., 2015). A high level of treatment for oil is achieved by applying air flotation, the advantage whereof also consists in the relative cheapness of the facility and the simplicity of operation. Flotation is a water treatment process that removes substances of a certain content, which is based on the ability of particles to adhere to bubbles of air and float with them to the surface (foam) layer.

Treatment facilities are generally constructed with account for the estimated flow of rainwater, with storm drains provided for excessive amounts of rainwater. When treatment facilities are overloaded during operation, rainwater runoff is regulated with a view to reducing its flow. For purposes of regulation, ponds and reservoirs are created near treatment facilities, with parts of the runoff being directed to said ponds and reservoirs.

The treatment system of the surface runoff that is diverted by the drain network into rivers and reservoirs can be created by constructing treatment facilities at the mouths of drains. 
Closed (chamber) facilities and treatment ponds, equipped with a system for collecting and removing oil waste and other pollutions, can provide for a significantly higher level of water treatment. These facilities are intended to capture floating litter of solid runoff and oil, washed off residential areas of the catchment basin by rainwater and meltwater, and after street washing.

Chamber facilities allow capturing solid pollutants and oil at drain headers with a small lowflow of water. The purpose of facilities for cleaning the runoff consists in ensuring a timely collection of pollution and bottom sediments in different ways, depending on the size and construction of facilities. Processing of wastewater sediments consists in the reduction of their moisture and volume (Helmers et al., 2012; Crites et al., 2014). Pollutants that are captured by grates are either removed from the treatment plant or fractioned and processed with the sediments from settlers. Desilting basin sand is dehydrated and either removed or washed free from organic pollutants and dried, after which it can be used in grading.

Places of discharge of surface wastewater into city watercourses and rivers by city aryk networks were found in Shymkent, according to the local terrain. There are 19 entry points of aryk networks and outlets of operating wells into the rivers that run in the city - Koshkar-Ata (10 discharge outlets), Karasu (8 discharge outlets), and Badam (1 discharge outlet). Discharge outlets also include the "Shymkent" and "Janashek" canals (considered a sewage system in this paper), which flow into the Koshkar-Ata River. The influxes of flume networks and drainage (ground) water into existing rivers allow determining the aggregate intermediate volume (over a certain period) of surface runoff that enters the watercourses after rains (Meyer and Lundy, 2014).

The term "wastewater" includes waters of various origin, content, and physical and chemical properties, which were used by humans for everyday and technological needs (Finger et al., 2013; Skaggs et al., 2012). During the process, the water was polluted, and its physical and chemical properties were changed. Wastewater has varying content and, consequently, properties. In terms of their nature of pollution, they are divided into organic, mineral, and biological. Organic pollutants are impurities of vegetable and animal origin. Mineral pollutants are quartz sand, clay, alkali, mineral acids and their salts, mineral oil, etc. Biological and bacterial pollutants are various microorganisms: yeast and mold, small algae and bacteria, including malignant ones - agents of typhoid fever, paratyphoid, dysentery, etc.

A peculiar feature of Shymkent's storm-water runoff is the high content of various pollutants in the runoff. Heavy rainfall washes off the territory all loose substances located in the soil. These may include household waste of residential houses, amenity spaces, industrial enterprises, foodservice outlets and medical institutions, industrial wastewater of technological processes - gas stations, garages, and carwashes. Household wastewater always contains a great amount of microorganisms that are products of human activity. Meteorological water has a high content of quartz sand, clay particles, litter and oil, which are washed off city streets. Pollution of industrial enterprises' territories causes the appearance in storm water of typical industrial impurities. Shymkent is also known for soft waterlogged grounds. In big industrial cities, such as Shymkent, wastewater may contain various impurities. In addition, wastewater is polluted by derivative products of vehicles, which enter waterbodies when washed by rainwater and meltwater (Qu et al., 2013; Mara, 2003; Crites et al., 2014). Therefore, wastewater treatment is an important task of the city that affects public health.

The authors' analysis confirmed the conclusions of Russian scientists, given below. For example, the high content of surface litter in riverine lands, which does great harm to riverine vegetation, soils, and the sanitary and esthetic state of watercourses. Heavy accumulation of metal, plastic, and other litter is typical of riverine land plots with private garages, which is also characteristic of Shymkent watercourses.

In order to solve the environmental problems of small rivers, it is necessary to conduct qualitative studies of all manmade complexes that enter their basins and have at least indirect impact thereon. This will enable the development of concrete environment protection measures, which will allow solving environmental problems of both rivers and cities. This assumes the optimization of diversion schemes for these waters.

Despite the fact that small rivers are the most numerous ones among watercourses, their fauna and flora are understudied. Most fundamental hydrobiological studies of small rivers were devoted to macrozoobenthos, while zooplankton was less studied. However, these components of water ecosystems are the main links in the energy transmission chain from producers to fish (Postel and Richter, 2012). When wastewater flows into small rivers, most such waterbodies become unsuitable for aquatic organisms of live. It also deteriorates the vegetation on riverbanks, which has a significant negative effect on the environment.

The level of a runoff's natural regulation significantly depends on the size of the catchment basin. In general, this dependence is not observed in the studied rivers due to other runoff factors; however, it is clearly seen in certain big rivers. This can be exemplified by the data on 11 stations on the Kuban River, from its upper reaches to Krasnodar (Fig. 1). Thus, the estimation of the maximum runoff of unstudied rivers in this methodological aspect can yield positive results only after the inclusion of another factor - the natural overregulation coefficient.

For example, in the Russian Federation, more than 65 thousand hydraulic structures are potentially dangerous and fall under the operation of 
the Federal Law "On Safety of Hydraulic Structures" No. 117-Ф3 dated July 21, 1997. The main ways of ensuring the safety of drainage structures are to maintain them in working order, which is the owners' obligation, to execute governmental supervision of the safety of drainage structures, which is performed by Rostechnadzor (the Federal Environmental, Industrial and Nuclear Supervision
Service of Russia), to declare the safety level of drainage structures, and to add drainage structures into the Russian register. According to the Russian Register of Hydraulic Structures in 2011, the safety level was normal in $39.3 \%$, reduced in $33 \%$, unsatisfactory in $11.9 \%$, and dangerous in $4.2 \%$. At that, it should be noted that the safety levels of most rivers in Kazakhstan are not yet measured.

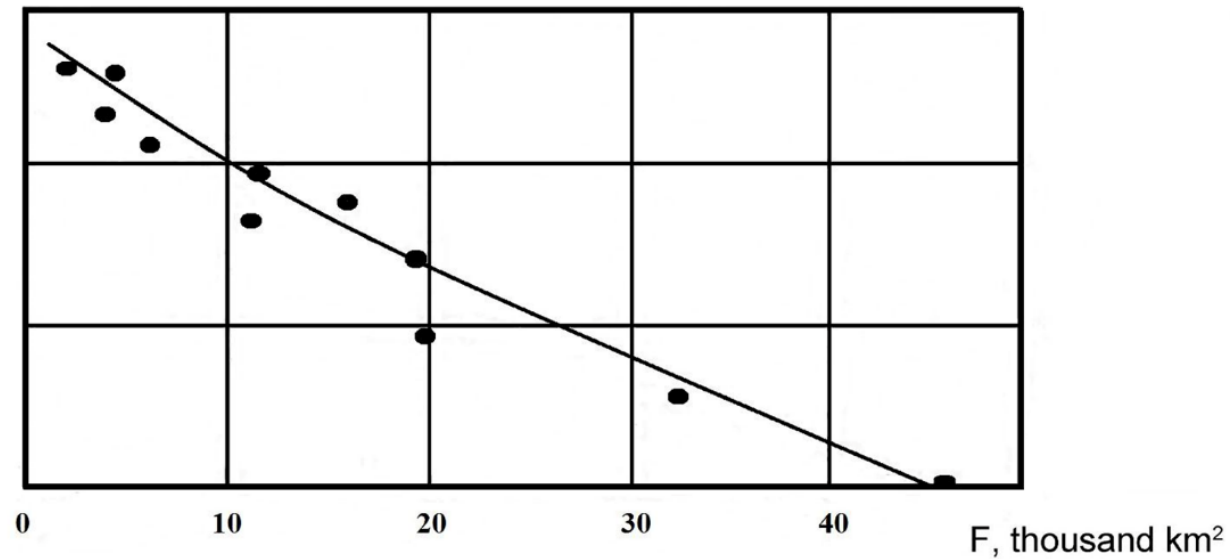

Fig. 1: Dependence of the natural overregulation coefficient $(K)$ on the size of the Kuban river catchment basin area

The studies in Shymkent concerning the problem of organizing a rational collection and treatment of runoffs, especially storm water ones, and the results of said studies allow solving similar problems in regions with conditions similar to Shymkent.

\section{Method}

The methodological and theoretical framework of the research included a set of methods relevant to the set goal, such as analysis, synthesis, systems approach, and analytical method. The research generalized the experience of studies on the problem at hand.

The chemical and physical properties of wastewater are presented based on the results of the conducted analysis. Water discharge outlet locations were indicated in Figs. 2, 3, 4, and 5.

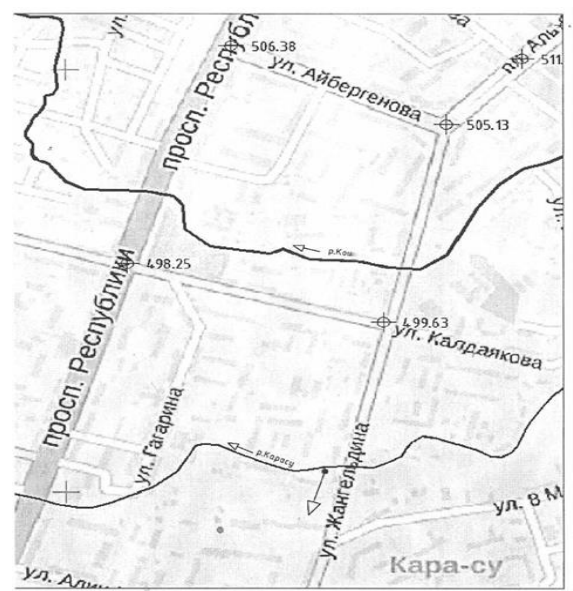

Fig. 2: Discharge outlet No. 3 into Karasu River, Jangeldin Str.

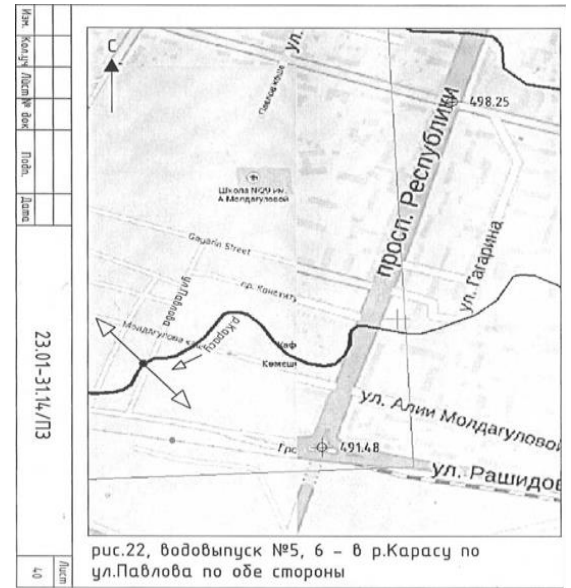

Fig. 3: Discharge outlets No. 5, 6 into Karasu River, Pavlova Str.

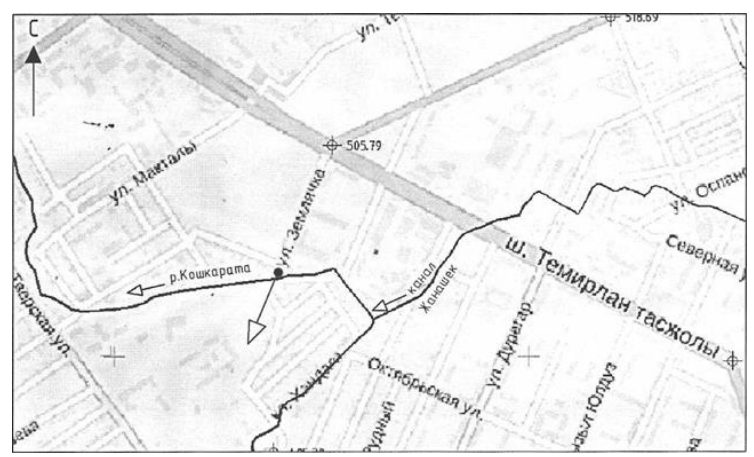

Fig. 4: Discharge outlet No. 8 into Koshkar-Ata River, Zemlyachki Str.

The water saprobity index was measured based on mathematical computations.

\section{Data, analysis, and results}

Foreign experience of studying small rivers, in particular, the experience of Russian scientists, 
proves that humankind significantly changed the natural state of the city terrain and hydrographic system. According to said scientists, hydrological objects can be divided into 2 groups: natural and artificial waterbodies. Back-filled watercourses can constitute an individual group.

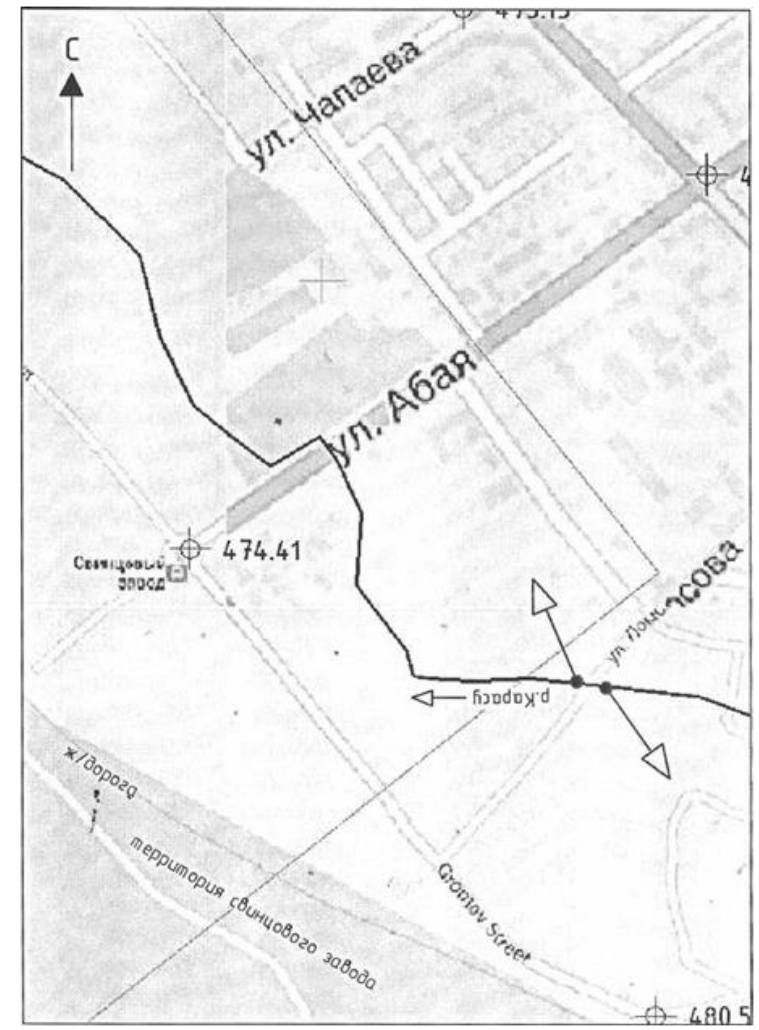

Fig. 5: Discharge outlets No. 7, 8 into Karasu River, Lomonosova Str.

Small rivers gradually pollute the Tsna River, which is also confirmed by studies made under the city environmental program. For example, the dry residue of water taken from the Studenets River was $665 \mathrm{mg} / \mathrm{l}$, from the Chumars River - $636 \mathrm{mg} / \mathrm{l}$, from the Sobachya River - $395 \mathrm{mg} / \mathrm{l}$, from the Zhigalka River - $371 \mathrm{mg} / \mathrm{l}$; the bottom sediments of Studenets River contain 107-10-4 mg/l of copper and 95·10-4 $\mathrm{mg} / \mathrm{l}$ of lead, of Zhigalka River - 20·10-4 mg/l of copper and $84 \cdot 10-4 \mathrm{mg} / \mathrm{l}$ of lead. These and other substances harmful to rivers enter the Tsna River and then flow beyond the region. A similar situation is observed in Shymkent (South Kazakhstan region), but with account for a closer proximity of groundwater, while 18 VDSs (vertical drainage systems) are physically incapable of reducing the level lower than $2 \mathrm{~m}$ below the surface.

Kazakhstan is characterized by the results of a protistological study (Meyer and Lundy, 2014). For example, 23 species of phototrophic euglenid flagellates belonging to five genera were found in samples from the Ishim River and Chertovo Lake. The leading genus in terms of species diversity is Euglena - 11 species. Trachelomonas and Phacus genera are both represented by five species. Lepocinclis and Monomorphina genera are both represented by one species. The fauna of euglenid flagellates in the Ishim River is represented by 16 species, which constitutes $69.6 \%$ of all species. The largest contribution in the Ishim River euglenid fauna is made by the Euglena genus, which is represented by eight species. In terms of quantity, the samples are dominated by the Phacus pleuronectes, Phacus acuminatus, and Monomorphina pyrum species. Other species are rarely encountered in the samples.

Among the discovered species, one species is characteristic of the oligosaprobic zone, which constitutes $6.3 \%, 6$ species are characteristic of the $\beta$-mesosaprobic zone (37.5\%), 2 species - of the $\beta$ - $\alpha$ mesosaprobic zone (12.5), and 5 species - of the $\alpha$ mesosaprobic zone $(31.3 \%)$. From the ratio of species with different indicator values, it follows that the Ishim River samples are dominated by $\beta$ mesosaprobic species. However, according to the saprobity index, the Ishim River is a $\alpha$-mesosaprobic waterbody (Table 1). 17 euglenid species were found in the Chertovo Lake samples, which constituted $74 \%$ of the overall number of species. In terms of species diversity, these samples are also dominated by the Euglena genus, which is represented by 10 species. The dominating species in terms of abundance are Euglena proxima, Trachelomonas hispida, and Tr. oblonga. Most euglenid species found in Chertovo Lake (58.8\%) are characteristic of the $\beta$-mesosaprobic zone, $23.5 \%$ of species - of the $\alpha$-mesosaprobic zone, and $11.8 \%$ of species are indicative of the oligosaprobic zone. However, according to the saprobity index, this waterbody is a $\alpha$-mesosaprobic one.

According to the authors, the investigated waterbodies are characterized by a high level of organic pollution. High saturation of Chertovo Lake waters with organic substances is probably caused by allochthonous pollution from human economic activities, since the poor development of macrophyte vegetation and poor communities of macroinvertebrates provides for an insignificant entrance of autochthonous organic substances into this waterbody. The high saprobity of the studied part of the Ishim River is probably determined by the entrance of allochthonous and autochthonous organic substances, caused by shoaling of the river and the growth of macrophyte vegetation.

Table 1: Characteristic of needles of pine-trees that grow in Karl Marx Str

\begin{tabular}{ccc}
\hline & Ishim River & Chertovo Lake \\
\cline { 2 - 3 } Saprobity index, $\mathrm{S}$ & 3.4 & 3.0 \\
Waterbody pollution zone by saprobity & $\alpha$-mesosaprobic & $\alpha$-mesosaprobic \\
\hline
\end{tabular}

These studies resulted in the following authors' conclusions:
1. The studied populations of animals and plants are characterized by high morphological 
character variability, the level whereof positively correlates with the manmade load rate.

2. The combined effect of several sources of pollution reduces the size, increases the number of damages of morphological characters, and reduces the germinating ability of plants' seeds.

3. The study discovered a high level of epigenetic polymorphism in city populations of animals, which reflects the specificity of development conditions and, consequently, the nature of pollution; however, the level does not exceed the critical value.

4. The studied waterbodies of Ishim city are characterized by a high level of organic pollution, primarily caused by human economic activities.

5. Preliminary study results evidence the need to monitor systematically the quality of the city environment, including both ecological and genetic studies (Meyer and Lundy, 2014).

These provisions are also applicable to the southern rivers - Syr Darya, Arys, and Keles.

In terms of the studied region, due to similar climatic conditions, it is also possible to acknowledge the accuracy of statements (Finger et al., 2013) that the main natural factors of forming mountain rivers' runoffs, including the maximal meltwater runoff, are the vertical zonation of the climate and its change from the West to the East. This allows determining the local dependences of maximal meltwater runoff rates on the average height of basins, and using them to estimate this runoff for unstudied rivers.

As an alternative method of estimating the maximal meltwater runoff, it is possible to use its connection with the annual one, but with an obligatory inclusion of a second factor - the natural overregulation coefficient of the runoff, which depends on the size of the catchment basin (Finger et al., 2013).

Maintaining the ecological state of watercourses at a level that is safe for the life and health of the population is one of the key tasks of modern urbanized territories. At that, the problem of controlling the quality of surface watercourse water is of primary importance (Bukovsky et al., 2011).

Chertoprud's method (Bukovsky et al., 2011) was used to evaluate the quality of water. The entire diversity of biotopes was examined at each station. The sampling of indicator organisms was carried out in the riverine part of the riverbed with a scoop-net and shovel. Bottom soil samples were backwashed until the wash water was clear. The analysis of samples was carried out directly at the place of collection. The belonging of organisms to a certain genus and, if possible, species was determined by observing the organisms in a thin layer of water. All data were then recorded in the examination report, while the discovered organisms were photographed on a digital camera. Water quality was evaluated by the saprobity index. The saprobity index was calculated by the following formula (Eq. 1):
$S=\frac{\sum s_{i} \times J_{i}}{\sum J_{i}}$

where, si is the saprobity of each indicator organism found in the sample (from 0 to 4 ), and Ji is the species' indicator weight. Saprobity and indicator weight values for discovered organisms were taken from the Table 1, compiled by Bukovsky et al. (2011).

Mishunisty's and Vostrov's application method (modified by Taranina) was used to study protease activity. The method suggests using an X-ray film, the emulsion whereof is destroyed by microorganisms, as an indicator of protease activity (Bukovsky et al., 2011).

The remaining operating life of water drainage structures allows determining their safe operating life, with or without restrictions, or deciding to repair or demolish structures or their individual elements (Skaggs et al., 2012). The remaining operating life for the safe operation of water drainage structures is determined by a systems analysis with a development of a block diagram of the dynamic system that has a number of subsystems. The main property that determined the life of a system was the reliability of its elements, i.e. the reliability and fail-safety throughout a certain term of operation. The reliability and fail-safety of the entire system was determined, proceeding from the condition that each system element can be in an either functional or failed state. The operability (reliability coefficient) of subsystem Rn.c. was determined by the following expression (Eq. 2):

$R_{n . c . j .}=1-F_{n . c .}$

where, Fn.c. is the general physical wear (failure) of a subsystem, which was determined by the following formula (Eq. 3):

$F_{n . c .}=\frac{\sum_{j=1}^{m} F_{k . j \cdot \cdot} z_{j}}{\sum_{j=1}^{m} Z_{j}}$

$F_{k . j .}$ is the physical wear of constructions of a j-type subsystem; $Z_{j}$ is the influence coefficients of j-type construction on the state of others; $m$ is the total number of construction types in the subsystem.

The physical wear of subsystem constructions was determined by expression (Eq. 4):

$F_{k . j .}=\sum_{i=0}^{n} F_{i} \cdot \frac{P_{i}}{P_{k}} F$

where, $\mathrm{Fi}$ is the physical wear of a construction part; $\mathrm{Pi}$ is the size (area and length) of the damaged part, expressed in sq. meters or meters; Pk is the size of the entire construction, expressed in sq. meters or meters; $\mathrm{n}$ is the number of damaged parts.

The estimated probability (5) of the operational conditions of system $\mathrm{R}\{\mathrm{j}(\mathrm{c})\}$, the structure function whereof is expressed by minimum paths and minimum cross-section, was determined by the following correlation (Eq. 5): 
$\prod_{j=1}^{k}\left(1-\prod_{i \in k j} q_{i}\right) \leq R[\varphi(\chi)] \leq 1-\prod_{j=1}^{P}\left(1-\prod_{i \in P_{j}} r_{i}\right)$

where, qi is the failure probability of subsystem $\mathrm{i}$; ri is the probability of fail-safe operation of subsystem $\mathrm{i}$; $\mathrm{P}$ is the total number of paths; $\mathrm{k}$ is the total number of cross-sections.

The general purpose of the operational monitoring of the technical state of drainage structures is to detect an increase in the level of physical wear, the reasons that determine their state, the actual operability of elements, to develop measures for improving various operational parameters, and to describe the technical state. The risk of accidents and defects is the highest at vulnerable objects, which include many water drainage structures - tunnels, canals, drain tunnels, flumes, and pipelines.

With a view to determining the estimated value of the maximum content, the reciprocal dilution of wastewater was calculated, which is equal to (Helmers et al., 2012) (Eq. 6):

$n=\frac{c_{w w}-c_{b g}}{c_{\max }-C_{b g}}$

where, $C_{w w}$ is the content of the substance in wastewater, $\mathrm{mg} / \mathrm{dm} 3 ; \mathrm{C}_{\max }$ is the estimated maximally polluted concentration in the control station; $\mathrm{C}_{\mathrm{bg}}$ is the content of the substance in the background station above the wastewater discharge, $\mathrm{mg} / \mathrm{dm} 3$.

The flow part with an $\mathrm{n} \cdot \mathrm{q}$ flow, where $\mathrm{q}$ is the wastewater flow, was considered the maximally polluted flow part, i.e. it was conventionally assumed that substance particles "pull up" to the maximum pollution point.

However, even if one were to assume an ideally accurate reciprocal dilution of wastewater in waterbodies, the $\mathrm{C}_{\max }$ concentration would only be achieved in the extreme point; therefore, the authors believe that there is no point in attributing it to the entire flow.

Studies of the design of gravity water drainage systems state that the system structure is generally seen as a tree, wherein the top is the users, and the roots are the holding basins of sewage treatment constructions (Everett et al., 2015). This network structure is effective during operation, cost-efficient, and does not require additional flow control systems. At the same time, the development of city territories requires solving the tasks of increasing the capacity of headers, which in its turn requires a rerouting of pipelines, a construction of pumping stations, and other measures, aimed at normalizing the operation of the water drainage system in general. More often than not, circle and dump headers are used for this purpose. Such headers have different structures (Fig. 6).

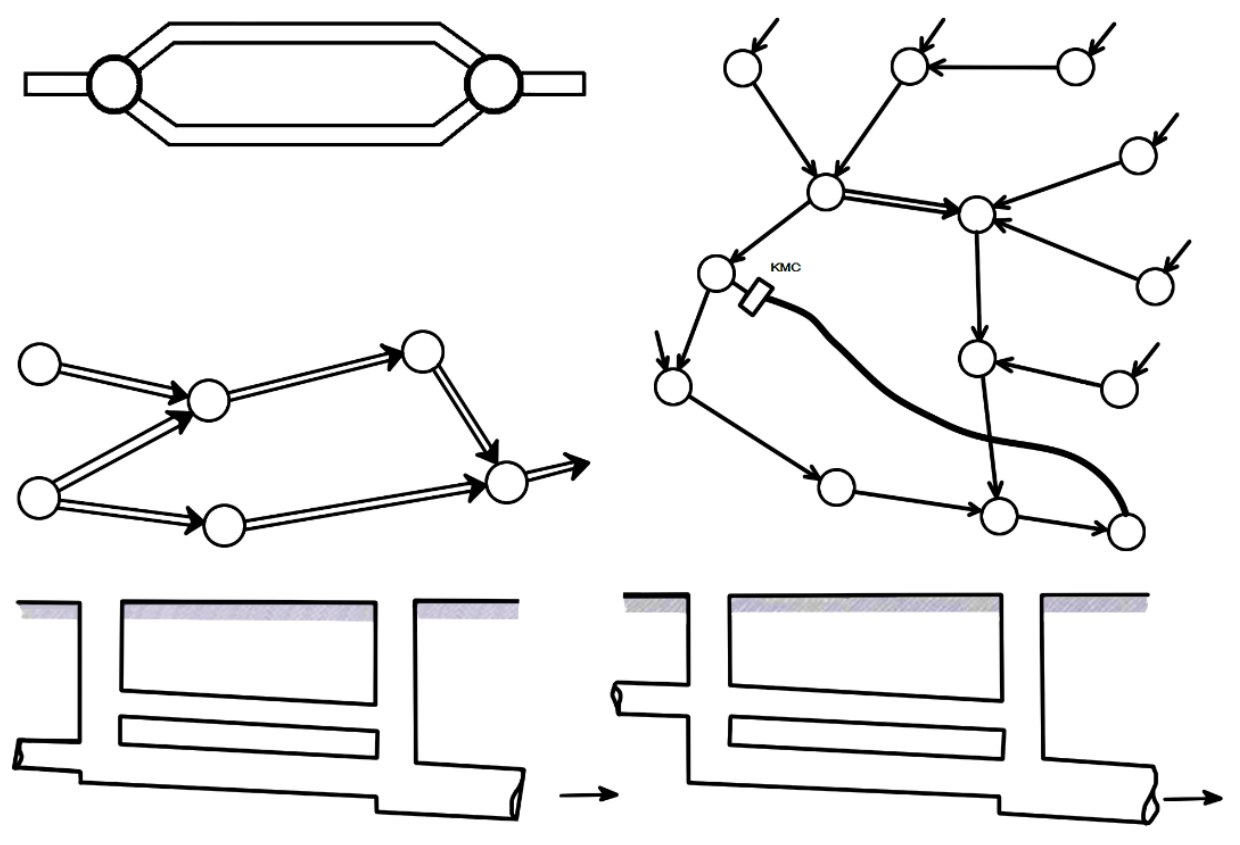

Fig. 6: Schematics of circle headers

Shymkent's advantage in this aspect is its terrain. Here, the water drainage system does not require the construction of pump stations. All runoffs can be drained and transported beyond the city along natural gulches and ravines. This is the only city in Kazakhstan, where water removal networks function without pumps.
In order to estimate the free flow of runoffs, authors used Antoine de Chézy's formula, which he obtained in 1775 (Eq. 7):

$Q=\omega \cdot c \cdot \sqrt{R i}$,

where $\omega$ is the waterway area, calculated by formula (Eq. 8):

$\omega=\frac{\pi d^{2}}{48}-\frac{d^{2}}{-}\left(\pi \frac{\alpha}{180}-\sin \sin \alpha\right)$, 
here, $\alpha$ is the central angle, equal to (Eq. 9):

$\alpha=2 \cdot \arccos \arccos \left(\frac{2 h}{d}-1\right)$

$\mathrm{h}$ is the depth of runoffs in the header); $\mathrm{C}$ is the Chézy coefficient, which is (Eqs. 10 and 11):

$C=\frac{R^{y}}{n}$,

$y=2.5 \cdot \sqrt{n}-0.13-0.75 \cdot \sqrt{R} \cdot(\sqrt{n}-0.1)$,

by the Manning formula $y=1 / 6 ; n$ is the roughness coefficient, which is assigned in accordance with the pipe material and ranges within (0.011-0.017); $\mathrm{R}$ is the hydraulic radius; $\mathrm{d}$, $\mathrm{i}$ is the diameter and inclination of the header.

If the header operates with a total cross-section, the flow in the pipeline can be calculated by formula (Eq. 12):

$Q_{n}=0.4 d^{2.5} \cdot i^{0.5} \cdot C_{n^{\prime}}$ i $>0$,

where, $C_{n}$ is the Chézy coefficient, calculated for the total cross-section. If $Q>Q_{n}$, the runoff flow mode will be pressure. Therefore, after estimating the flows, they can be correlated with $\mathrm{Q}_{\mathrm{n}}$ to determine the headers and even circuits that will operate in pressure mode. The following formula is suggested to determine the normal depth of $\mathrm{h}$ in the header (Eq. 13):

$\left(\frac{2}{Q_{n}}+0.22\right) \frac{d}{1.34}=h$

for $0.25 \leq \frac{h}{d \leq} 0.9$.

For a more precise calculation, value $\mathrm{h}=\mathrm{P}-\mathrm{ZH} 2$ will determine the height of the waterway area (Eq. 14):

$\alpha=2 \cdot \arccos \arccos \left(\frac{2 \cdot\left(P-Z_{\mathrm{H} 2}\right)}{d}-1\right)$.

Thus, for pressure and gravity headers, the following system of equations is obtained (Eq. 15):

$$
\left\{\begin{array}{c}
P-Z_{k 1}+Q_{1}^{2} \cdot\left[\frac{0.25}{d_{1}^{4}}+\frac{0.08 \lambda_{1} \cdot l_{1}}{d_{1}^{5}}\right], \\
P=Z_{H 2}+\left(\frac{Q_{2}}{Q_{n}}+0.22\right) \frac{d_{2}}{1.34}, \\
\mathcal{Q}=Q_{1}+Q_{2} .
\end{array}\right.
$$

After determining the flow by headers, it is possible to calculate the normal depth in the top header and to draw a free water surface curve. It is worth noting that the equation of runoff flow into the top header will be transcendent as regard to $P$; therefore, equation system (15) will be solved by successive approximation.

The authors estimated the volume of surface water, discharged into the Badam, Koshkar-Ata and Karasu rivers, in accordance with hydrological and climatic statistical data for the last 20 years, with the use of the methods of estimating the discharge of storm runoffs from the territory of settlements and enterprises.

For discharge outlets that divert mixed water (drainage and rain), the flow from the operation of vertical drainage wells was also accounted for. The volume of drained water complied with special water use permit No. 344/ACחР dated 25.01.2013. Considering that the designed flow rate of all wells is virtually identical, the volume of discharged drainage water into each waterbody was determined in proportion to the number of currently operating wells. The drainage runoff of 18 wells into the "Janashek" canal was $0.383 \mathrm{~m} 3 / \mathrm{sec}, 1378.0 \mathrm{~m} 3 / \mathrm{hr}$, or 503.0 thousand $\mathrm{m} 3 /$ year. The runoff into the Koshkar-Ata River was $1.07 \mathrm{~m} 3 / \mathrm{sec}, 3858.0 \mathrm{~m} 3 / \mathrm{hr}$, or 1409.0 thousand $\mathrm{m} 3 /$ year.

The average annual volume of surface wastewater that was generated in residential and industrial areas during rains and snow melting is determined by formula (Eq. 16):

$W y=W r+W m$

where, $\mathrm{Wr}, \mathrm{Wm}$ is the average volume of rainwater and meltwater, $\mathrm{m} 3$.

The average annual volume of rainwater (Wr) and meltwater $(\mathrm{Wm})$ that flow form the residential and industrial areas is determined by the following formulas (Eqs. 17 and 18):

$W r=10 \mathrm{hr} \Psi r F$

$W m=10 \mathrm{hm} \Psi \mathrm{m} F$

where $\mathrm{F}$ is the total runoff area, ha; $\mathrm{hr}$ is the precipitation depth, $\mathrm{mm}$, during the warm period of the year, which is found in Table 2 of the Building Regulations of the Republic of Kazakhstan 2.04-012010; $\mathrm{hm}$ is the precipitation depth, $\mathrm{mm}$, during the cold period of the year (this determines the total annual volume of meltwater) and the water equivalent of the snow cover by the start of snow melting, which is found in Table 1 of the Building Regulations of the Republic of Kazakhstan 2.04-012010; $\Psi \mathrm{r}$ and $\Psi \mathrm{m}$ is the total runoff coefficient of rainwater and meltwater, respectively.

When determining the average annual volume of rainwater $(\mathrm{Wr})$ that flows from residential areas, the total runoff coefficient ( $\Psi \mathrm{r}$ ) for the total runoff area was calculated as weighted average of individual values for runoff areas with different surface types.

When determining the average annual volume of meltwater, the total runoff coefficient $(\Psi \mathrm{M})$ from residential and industrial areas, taking into account snow removal and loss of water due to partial absorption by water-permeable surfaces during thaw, can be taken within 0.5-0.7.

Apart from the abovementioned 19 places of surface wastewater discharge from the city aryk network and drained groundwater, it is necessary to mention separately 20 more discharge outlets - a

network of gullies in the northern part of the city, whereby storm water is removed from all new city 
districts that were built beyond the Ryskulova Str.

over the part 10-15 years.

Table 2: Estimated average annual volume of surface wastewater in the Koshkar-Ata River

\begin{tabular}{|c|c|c|c|c|c|c|c|c|c|}
\hline $\begin{array}{l}\text { Discharge } \\
\text { outlet No. }\end{array}$ & $\begin{array}{c}\text { Runoff area, } \\
\text { ha }\end{array}$ & $\mathrm{hr}$ & hm & $\begin{array}{c}\text { Runoff } \\
\text { coefficient }\end{array}$ & $\mathrm{Wr}$ & Wm & Wtot & $\mathrm{m} 3 / \mathrm{sec}$ & $\mathrm{m} 3 / \mathrm{hr}$ \\
\hline 1 & 621 & 208 & 368 & 0.5 & 645840 & 1142640 & 1788480 & 6 & 7225 \\
\hline 3 & 337 & 208 & 368 & 0.5 & 350480 & 620080 & 970560 & 3.3 & 3960 \\
\hline 4 & 248 & 208 & 368 & 0.5 & 257920 & 456320 & 714240 & 2.4 & 2913 \\
\hline 6 & 2.1 & 208 & 368 & 0.5 & 2184 & 3864 & 6048 & 0.038 & 47 \\
\hline 7 & 930 & 208 & 368 & 0.5 & 967200 & 1711200 & 2678400 & 6 & 7200 \\
\hline 8 & 1.9 & 208 & 368 & 0.5 & 1976 & 3496 & 5472 & 0.035 & 44 \\
\hline \multicolumn{10}{|c|}{ Estimated average annual volume of surface wastewater in the Badam River } \\
\hline 1 & 0.6 & 208 & 368 & 0.5 & 624 & 1104 & 1728 & 0.011 & 14 \\
\hline \multicolumn{10}{|c|}{ Estimated average annual volume of surface wastewater in the Karasu River } \\
\hline 1 & 1.5 & 208 & 368 & 0.5 & 1560 & 2760 & 4320 & 0.038 & 46 \\
\hline 2 & 1.8 & 208 & 368 & 0.5 & 1872 & 3312 & 5184 & 0.046 & 55 \\
\hline 3 & 2.2 & 208 & 368 & 0.5 & 2288 & 4048 & 6336 & 0.056 & 67 \\
\hline 4 & 2.1 & 208 & 368 & 0.5 & 2184 & 3864 & 6048 & 0.053 & 64 \\
\hline 5 & 2 & 208 & 368 & 0.5 & 2080 & 3680 & 5760 & 0.051 & 61 \\
\hline 6 & 1.7 & 208 & 368 & 0.5 & 1768 & 3128 & 4896 & 0.043 & 52 \\
\hline 7 & 1.6 & 208 & 368 & 0.5 & 1664 & 2944 & 4608 & 0.04 & 49 \\
\hline 8 & 1.6 & 208 & 368 & 0.5 & 1664 & 2944 & 4608 & 0.04 & 49 \\
\hline
\end{tabular}

However, the gullies are scattered, i.e. they run in irregular zigzags along the entire northern part of the city and further west. Each individual area of the single chain of gullies has its own name - the Fox Gulley (Albasty-Say), Kuruburzhar-Say, etc. The gullies are quite deep. The elevation difference of gullies is, according to marks, $515.75-508.15=7.60$ $\mathrm{m}$. Due to the length of the gulley network, it is difficult to establish a single centralized specific discharge place for the accumulated wastewater, similar to the abovementioned 19 discharge outlets within the city boundaries. However, it is necessary to choose such a place, with a view to constructing treatment facilities in accordance with the legal requirements. This also concerns those of the 19 places within the city boundaries, the surface water runoffs from which are polluted the most.

\section{Discussion}

Methods of calculating rainwater; Hydrological characteristics: The limiting runoff strength formula, in accordance with Paragraph 7.44 of the International Set of Rules 3.04-101-2005, was used to calculate the maximum runoff rate (Eq. 19):

$Q 1 \%=A 1 \% \times \varphi \times \mathrm{H} 1 \% \times F$

Where, Q1\% is the maximum instant flow rate of the rainfall flood, $\mathrm{m} / \mathrm{sec}$; $\mathrm{A} 1 \%$ is the maximum runoff rate with an annual exceedance probability of $1 \%$, expressed in fractions of multiplication ( $\varphi \times \mathrm{H} 1 \%)$, where $\varphi$ is the composite runoff coefficient and $\mathrm{H} 1 \%$ is the daily precipitation depth of $1 \%$ probability, which determined in accordance with the Shymkent weather station data by means of mathematical statistics, and which is $84 \mathrm{~mm}$; $\mathrm{F}$ is the catchment basin area, $\mathrm{km}(1 \mathrm{~km}=100 \mathrm{ha})$.

The composite runoff coefficient is determined by Eq. 20:

$\varphi=\frac{C_{2} \times \varphi_{0}}{\left(F+I_{B}\right)^{n 3}} \times\left(\frac{G_{B}}{50}\right)^{n_{2}}$ where, IB is the inclination of catchment slopes, determined by topographical maps; $\varphi_{0}$ is the runoff coefficient, which is determined for a given catchment basin by weighting, since it has to account for areas with different runoff coefficients of lawns with $\varphi_{0}=0.1$; from smallholdings $-\varphi_{0}=0.2$; to asphalted plots $-\varphi_{0}=0.7-0.9 ; n_{2}$ is the power coefficient, which is determined, depending on the mechanical content of soils and the natural area; $n_{3}$ is the power coefficient for "our" natural area -0.11 , $C_{2}$ is the empirical coefficient for "our" natural area 1.3 .

In order to determine the $\mathrm{A} 1 \%$ value, it is necessary to calculate the hydro morphometric characteristics of slopes $\left(\varphi_{s l}\right)$ and the bed $\left(\varphi_{b}\right)$, in accordance with the recommendations, provided in the International Set of Rules 3.04-101-2005.

In order to calculate the maximum runoff rate in Shymkent, the city was divided into four zones, where catchment areas were lied between canals and rivers: the first zone was between Karasu River and Koshkar-Ata River, the second zone was between Koshkar-Ata River and Janashek canal, the third zone was between the Janashek and Shymkent canals, and the fourth zone was between the Shymkent canal and the Badam main canal.

In each zone, three typical catchments were distinguished, for which the catchment areas and their morphometric characteristics $\varphi_{r}$ and $\varphi_{s l}$ were determined; the composite runoff coefficient was identical $-\varphi_{\text {ro }}-0.25$. A1\% values were determined for all catchments.

The $\mathrm{A} 1 \% \times \mathrm{H} 1 \%$ expression is the maximum runoff rate of $1 \%$ probability (M1\%); $\mathrm{M} 1 \%=\mathrm{A} 1 \% \times$ $\mathrm{H} 1 \%$ :

- for the first zone, it is $\mathrm{M} 1 \%=0.8 \div 1.0 \mathrm{~m} 3 / \mathrm{sec}$ from $1 \mathrm{~km}$;

- for the second zone $-\mathrm{M} 1 \%=0.84 \div 0.94 \mathrm{~m} 3 / \mathrm{sec}$ from $1 \mathrm{~km}$;

- from the third zone $-\mathrm{M} 1 \%=0.8 \div 1.1 \mathrm{~m} 3 / \mathrm{sec}$ from $1 \mathrm{~km}$; 
- for the fourth zone - M1\%= $1.1 \div 1.4 \mathrm{~m} 3 / \mathrm{sec}$ from $1 \mathrm{~km}$.

In general, the runoff rate increases on steeper slopes and smaller catchment areas.

By knowing the catchment area of the land plot and the runoff rate, it is possible to calculate the estimated water flow rate of $1 \%$ probability, which flows from this area (Eq. 21):

$Q 1 \%=\mathrm{M} 1 \% \times F$

For a more precise calculation, it is necessary to perform the estimation for each individual territory, since the runoff coefficient can vary in the city, as was mentioned above, from $\varphi_{0}=0.1$ to $\varphi_{0}=0.9$.

During the calculation of the maximum flow of water of the rainfall flood, which is accumulated beyond the city by designed flumes, it was assumed that these flumes, which cross the city east to west in the northern, central, and southern parts of the city, are a river network with a catchment area of 152 $\mathrm{km}^{2}$. The same limiting runoff strength formula was used to determine the maximum flow of water of the rainfall flood, where:

$\varphi_{s l}=23 \% \mathrm{o}, \varphi_{0}=7 \% \mathrm{o}, \varphi=0.14, \varphi_{\mathrm{c \kappa}}=200 \mathrm{~min}$.

At $\mathrm{A} 1 \%=0.012$ and $\mathrm{A} 10 \%=0.011$, the water flow, removed from the city by spillways will be:

- $\mathrm{Q} 1 \%=\mathrm{A} 1 \% \times \varphi \times \mathrm{H} 1 \% \times \mathrm{F}=0.012 \times 0.14 \times 84 \times$ $152=21.5 \mathrm{~m} 3 / \mathrm{sec}$.

- $\mathrm{Q} 10 \%=\mathrm{A} 10 \% \times \varphi \times \mathrm{H} 10 \% \times \mathrm{F}=0.011 \times 0.14 \times 52$ $\times 152=12.1 \mathrm{~m} 3 / \mathrm{sec}$

- $\mathrm{p}=1 \%$ - frequency of occurrence is 1 per 100 years, applied for the examination of importance category IV structures;

- $p=10 \%$ - frequency of occurrence is 1 per 10 years; this variant was taken as the estimated one.

\section{Conclusion}

According to observation data, a rotation of several rainfall floods is possible in Southern Kazakhstan rivers, while in unfavorable years, they can occur in succession with 3 or 4 peaks (1969 model), but with 1.2-2 times smaller volumes.

Also possible are catastrophic floods, as that of 1945, when the Koshkar-Ata River flow exceeded the average volume by 25 times.

According to the hydrological estimation of the maximum runoff, a maximum flow rate of the rainfall flood with $10 \%$ probability of the composite runoff of $12.1 \mathrm{~m} 3 / \mathrm{sec}$ is taken into account. It is distributed among sump headers: the Central part of the city the basins of the Shymkent and Janashek canals, and
Koshkar-Ata River - $4.5 \mathrm{~m} 3 / \mathrm{sec}$; the Northern part of the city - the basins of the Kuruburzhar-Say watercourse and the Fox Gulley (Albasty-Say) - 5 $\mathrm{m} 3 / \mathrm{sec}$; the Southern part of the city - the basin of Karasu River and the right bank of Badam River - 2.6 $\mathrm{m} 3 / \mathrm{sec}$.

Wastewater treatment is important for the environment, since polluted water enters the ecosystem, which causes mass dying-out of living organisms. The 19 places of surface wastewater investigated during this research should be repaired and modernized.

This research can serve as a theoretical framework for follow-up studies that aim to create a single wastewater treatment system.

\section{References}

Bukovsky MYe, Kolomeytseva NN, Klokov AYu, and Oleynikov AA (2011). Evaluation of water quality of the Tsna River basin surface watercourses by bioindication. Tambov University Reports. Natural and Technical Sciences, 2(16): 638-642.

Crites RW, Middlebrooks EJ, and Bastian RK (2014). Natural wastewater treatment systems. CRC Press, Boca Raton, Florida, USA.

Everett G, Lamond J, Morzillo AT, Chan FKS, and Matsler AM (2015). Sustainable drainage systems: Helping people live with water. Proceedings of the ICE-Water Management, 169(2): 94-104.

Finger D, Hugentobler A, Huss M, Voinesco A, Wernli H, Fischer D, and Vennemann T (2013). Identification of glacial meltwater runoff in a karstic environment and its implication for present and future water availability. Hydrology and Earth System Sciences, 17(8): 3261-3277.

Helmers M, Christianson R, Brenneman G, Lockett D, and Pederson C (2012). Water table, drainage, and yield response to drainage water management in southeast Iowa. Journal of Soil and Water Conservation, 67(6): 495-501.

Mara D (2003). Domestic wastewater treatment in developing countries. Earthscan, Routledge, UK.

Meyer B and Lundy L (2014). Integrated water cycle management in Kazakhstan. Al Farabi Kazakh National University Publishing House, Almaty, Kazakhstan.

Nekhoroshkov A (2016). Moral Dimensions of Youth's World View in Multi-Ethnic Environment. Mathematics Education, 11(6):1761-1771.

Postel S and Richter B (2012). Rivers for life: Managing water for people and nature. Island Press, USA.

Qu X, Alvarez PJ, and Li Q (2013). Applications of nanotechnology in water and wastewater treatment. Water Research, 47(12): 3931-3946.

Saldaeva MN, Kudryashov AV, Magomadova TL, Sikorskaya GP, Evtodieva TE, and Charaeva MV (2016). The analysis of institutional environment for development of a public-private partnership in the sphere of environmental protection in the samara region. International Journal of Environmental and Science Education, 11(14): 6934-6948.

Skaggs RW, Fausey NR, and Evans RO (2012). Drainage water management. Journal of Soil and Water Conservation, 67(6): 167A-172A. 